\title{
Assessment of Used Formulae for Sonographic Estimation of Fetal Weight in Sudanese Population
}

\author{
Caroline Edward Ayad1, Ahmed Abdelrahim Mohammed Ibrahim², \\ Mohamed Elfadil Mohamed Garelnabi', Bushra Hussein Ahmed ${ }^{3}$, Elsafi Ahmed Abdalla1, \\ Mohammed Ahmed Elshiekh Saleem ${ }^{1}$ \\ ${ }^{1}$ College of Medical Radiological Science, Sudan University of Science and Technology, Khartoum, Sudan \\ ${ }^{2}$ Faculty of Radiology Science and Medical Imaging, Alzaiem Alazhari University, Khartoum, Sudan \\ ${ }^{3}$ College of Medical Radiological Science and Nuclear Medicine, The National Rabat University, Khartoum, \\ Sudan \\ Email: Carolineayad@yahoo.com
}

Received 28 April 2016; accepted 6 June 2016; published 9 June 2016

Copyright (C) 2016 by authors and Scientific Research Publishing Inc. This work is licensed under the Creative Commons Attribution International License (CC BY). http://creativecommons.org/licenses/by/4.0/

\section{(c) (i) Open Access}

\section{Abstract}

The objective of this study is to assess commonly used formulae (Sheppard, Campbell, Hadlock I, II, III, and IV) for estimation of fetal weight in Sudanese population. A descriptive cross-sectional study was conducted at Saudi Hospital-Khartoum-Sudan; from December 2015 to April 2016. The study included 225 singleton pregnancies. The fetal biometry-Biparietal diameter (BPD), head circumference (HC), abdominal circumference (AC), femur length (FL) and actual birth weights (ABW) were taken. Statistical analysis showed significant results at $p \leq 0.005$. Results showed that the significant highest positive correlation between the ABW and the EFW/Kg was seen in the Hadlock I, III and IV equations having an equal values (0.951) followed by Hadlock II (0.946), Sheppard (0.872) and lastly Campbell (-0.925) with significant high degree of negative correlation. The new established equation FFW $_{\text {FLHCAC }}$ is the best formula identified in our study to predict Sudanese babies weight ranged between $1.86 \mathrm{Kg}$ to $3.987 \mathrm{Kg}$.

\section{Keywords}

Ultrasonography, Fetal Weight, Gestational Age

\section{Introduction}

Ultrasonography is used to estimate the fetal weight and is often used as a surrogate to actual birth weight. Many

How to cite this paper: Ayad, C.E., Ibrahim, A.A.M., Garelnabi, M.E.M., Ahmed, B.H., Abdalla, E.A. and Saleem, M.A.E. (2016) Assessment of Used Formulae for Sonographic Estimation of Fetal Weight in Sudanese Population. Open Journal of Radiology, 6, 113-120. http://dx.doi.org/10.4236/ojrad.2016.62017 
ultrasound estimated fetal weight (EFW) formulae have been deliberated and these are based on different fetal biometric parameters [1]. Fetal weight estimation has a significant bearing on administration judgment in labor, thereby improving prenatal outcome [2]. Low and extreme fetal weight is associated with increased risk of complication during pregnancy, labor and neonatal life [3]-[7]. Therefore detection of poor fetal growth or fetal macrosomia is of greatest significance in obstetrics. Numerous formulae have been published for the purpose of estimating fetal weight from a variety of sonographically obtained biometric measurements. Biparital diameter (BPD), head circumference (HC), Abdomen circumference (AC) and femur length (FL), most commonly, a combination is used [8] [9]. An accurate means of estimating fetal weight using ultrasonography was first described by Campbell 1975 [8]. The most popular formulae are Sheppard, Warsof's [10] with Sheppard's modification [11] and Hadlock [9] [12]. These formulae are included in most ultrasound equipment packages. Even though, Sonographic machines offer various different formulae for estimation of fetal weight. To the best of our knowledge there is no study which recommends the best formula for Sudanese pregnant ladies in the open literature was established. This study is conducted to determine the applicability of these various formulae, developed in the West, in estimating fetal weight in Sudanese population. According to the results the most suitable formula can be determined or if results are not significantly different any formula can be used without predilection. The formatter will need to create these components, incorporating the applicable criteria that follow.

\section{Materials and Methods}

\subsection{Study Population}

The data of this study were obtained from 225 Sudanese pregnant ladies with uneventful pregnancies (Normal); attending the designated study area during the study period, with singleton pregnancies at second and third trimester with viable fetus. Pregnancies with established diagnosis of hypertension, diabetes were excluded.

\subsection{Data Collection Tools}

Verbal consent was firstly obtained from all potential participants. The aims, benefits of the present study were explained to all participants in details. Medical, obstetric and gynecological history of all study subjects posing as (sample) will be thoroughly reviewed directly from participants themselves and those with conditions that may in any way, alter the findings of the current study were excluded.

\subsection{Measuring of Fetal Weight}

Sonographic examination was obtained for all participants in supine position using Ultrasound machine with curvilinear probe and transducer frequency of $3.5 \mathrm{MHz}$. The procedures were explained for participants and were asked to evacuate the urinary bladder before the scanning. Singleton pregnancy of (60 fetuses out of 255), those who delivered within 2 days of the ultrasonography examination by elective caesarian section or of normal labor were included on the study to measure their fetal weights after delivery using weight caliber. Fetuses with congenital anomalies, the biometric measurements of those, which were unable to ascertain due to reasons like deeply engaged head, were excluded from the study.

Biparietal diameter (BPD) measurement was taken. The head circumference (HC) was calculated using electronic ellipse available on the ultrasound scanner. The fetal abdominal circumference (AC) was measured in standard transverse planes at the levels of the stomach and umbilical vein-ductus venous complex. The femur length (FL) was measured from the proximal end of the greater trochanter to the distal metaphysis. Estimated fetal weight from each equation was calculated separately using basic biometric values for estimation of fetal weight measured automatically by the ultrasound machine.

The fetal biometric measurements which were taken previously for the planned delivery were collected in a data sheet. The actual birth weights for 60 babies out of 225 fetuses were also entered into the data sheet after the delivery of the fetuses.

With the collected measurements done by ultrasound machine and the estimated measurement done for every fetus, 6 different EFWs formulae (Hadlock et al., I, П, Ш, 1V, Campbell and Sheppard) [13] were tested. The validity of these 6 formulas in predicting the actual FW in the study population was tested after comparison with the actual fetal weights. The fetal biometry necessary for measuring the fetal weight was as follows \{Sheppard (BPD, AC), Campbell (AC), Hadlockl-(AC, FL), Hadlock II (BPD, AC, FL), Hadlock III (HC, AC, FLx HC), 
Hadlock IV (BPD, HC, AC, FL)\} [13].

\subsection{Measuring Birth Weight}

Actual birth weights of all the fetuses were taken separately. Birth weight measurements were taken using a properly calibrated digital weighing machine. The birth weights were measured by trained nurse. It is known that delays of more than 7 days between the ultrasound examination and birth might elevate error rates falsely, because each fetus has a variable rate of continued growth after ultrasound examination until birth. Thus, the method optimized the accuracy of ultrasound EFW by avoiding the confounder of continued fetal growth after ultrasound examination.

\subsection{Data Analyses}

Data were analyzed using Statistical Package of Social Sciences (SPSS) (Inc., Chicago, Illinois version 16). The data obtained were analyzed statistically by computing descriptive statistics: Mean, \pm SD values and percentages. Paired t-test was used for testing the differences between the formulae results. The difference at value of $\mathrm{p}<$ 0.005 will be considered significant.

\section{Results}

The results of this study are presented in the following tables and figures. The results showed the assessment of various formulae used to estimate fetal weight sonographically. Correlations between the estimated fetal weight measured by ultrasound machine and estimated fetal weight measured by 6 Ultrasound equations were achieved. The actual birth weight results were correlated with the tested formulae. Results showed no significantly difference between the EFW/Kg and the six equations and the actual birth weight. New Sudanese equation for estimation of fetal weight was established and it works well for Sudanese, since the fetal biometry used were indigenous; therefore it is the best formula identified to predict Sudanese babies weight ranged between $1.86 \mathrm{Kg}$ to $3.987 \mathrm{Kg}$. The new formula can be used without predilection.

\section{Discussion}

Many different formulae have been published in the literature for EFW, and various studies have been done to evaluate the accuracy of these formulas [14]-[16].

Ultrasound scan is a most popular investigation in the obstetric practice. Serial measurements of estimated fetal weight were highly developed to the one single measurement of EFW in prediction of fetal growth [17]. Determination of fetal weight by ultrasonography depends on the formulae which were designed to predict fetal weight. These formulae use one or few fetal biometric measurements for calculation of fetal weight [13].

We considered the equations of Sheppard, Campbell, Hadlock I, II, III and IV because these are the commonly used formulae to estimate fetal weight and were included in the study. In the current study a significant high degree of positive correlation (at $\mathrm{p} \leq 0.005$ ) between the ABW and the EFW/Kg was seen. In Hadlock I, III and IV equations scores equal values (0.951) followed by Hadlock II (0.946), Sheppard (0.872) and lastly Campbell (-0.925) with significant high degree of negative correlation (Table 1, Table 2). The contribution of the tested formulae of Hadlocks formulae from I-IV among the six tested formulae to estimate the Sudanese fetal weight was found to be (91\%, $89 \%, 91 \%$ and $91 \%)$ respectively. The formula of Sheppard had the lowest contribution $73 \%\left(\mathrm{R}^{2}=0.733\right)$ while Campbell was $85 \%\left(\mathrm{R}^{2}=0.849\right)$. This was noticed in Figures 1-6.

Most of the previous studies had shown that there was a positive correlation between the ABW and EFW by different formulae. The study by Nahum G G [18] had shown that the Hadlock and Sheppard formulae had a positive correlation with ABW in which Hadlock formula had a better correlation with ABW than Sheppard. A study done in Singapore showed that the Hadlock formula was originally derived from an American population, it was equally useful in South-East Asian population [19].

In the published literature authors mentioned that Hadlock IV has the highest sensitivity, although Campbell formula has the lowest sensitivity to predict babies less than $2.5 \mathrm{~kg}$. However in a study done by Siemer J in Germany showed that Hadlock II and III formulae best to predict EFW in fetuses less than $2.5 \mathrm{~kg}$ [20]. And for the birth weight category of more than $3.5 \mathrm{~kg}$ the Sheppard has the highest sensitivity and the Hadlock IV has the lowest sensitivity for detection of a great newborn. Even though the Hadlock IV is the best formula identified 
Table 1. Shows the Actual birth weight and estimated fetal weight measured by 6 ultrasound equations for measuring of the fetal weight and the new equation results.

\begin{tabular}{cccccccc}
\hline & Campbell & Sheppard & HadlockI & HadlockП & HadlockW & HadlockIV & *EFW_FIHCAC \\
\hline${ }^{* *}$ Estimated fetal weight & 3.55 & 3.38 & 2.85 & 2.93 & 2.63 & 1.77 & 3.09 \\
Actual birth weight & 3.13 & 3.13 & 3.13 & 3.13 & 3.13 & 3.13 & 3.13 \\
\hline
\end{tabular}

"EFW_FLHCAC = New Established Equation. ${ }^{* *}$ The estimated fetal weight was measured/Kg using different fetal weight formulae .The fetal biometry necessary for measuring the fetal weight was as follows \{Sheppard (BPD, AC), Campbell (AC), Hadlock l (AC, FL), Hadlock II (BPD, AC, FL), Hadlock III (HC, AC, FLx HC), Hadlock IV (BPD, HC, AC, FL) and the new equation used for Sudanese created from the regression equation was applied including the fetal biometry (FL, AC and HC) \} The correlation between the estimated fetal weight measured by all equations and the actual fetal weight showed significant relation at $\mathrm{p} \leq 0.000$.

Table 2. Shows the Paired Samples Correlations between the estimated fetal weight measured by ultrasound machine and estimated fetal weight measured by 6 ultrasound equations for measuring of the fetal weight. (Correlation is significant at $\mathrm{p} \leq$ 0.005).

\begin{tabular}{|cccc}
\hline \multicolumn{2}{c}{$\begin{array}{c}\text { Correlations Between the estimated fetal weight measured by ultrasound machine And Estimated Fetal Weight Measured } \\
\text { By } 6 \text { Ultrasound Equations }\end{array}$} & Sig. $^{*}$ \\
\hline Campbell \& EFW/Kg & N & Correlation & 0.000 \\
Sheppard \& EFW/Kg & 225 & -0.925 & 0.000 \\
Hadlock I \& EFW/Kg & 225 & 0.872 & 0.000 \\
Hadlock I \& EFW/Kg & 225 & 0.951 & 0.000 \\
Hadlock Ш \& EFW/Kg & 225 & 0.946 & 0.000 \\
Hadlock IV \& EFW/Kg & 225 & 0.951 & 0.000 \\
\hline
\end{tabular}

*All equations showed significant correlation with fetal weight measured by ultrasound machine.

Table 3. Shows the Correlations Coefficients between the estimated fetal weight/Kg (Dependant variable) and measured FL, $\mathrm{HC}$, and AC.

\begin{tabular}{|c|c|c|c|}
\hline \multirow{2}{*}{ Model } & Coefficient & $\mathbf{t}$ & Sig. ${ }^{*}$ \\
\hline & B & & \\
\hline (Constant) & -1.844 & -11.756 & 0.000 \\
\hline FL & 0.661 & 5.575 & 0.000 \\
\hline $\mathrm{HC}$ & -0.470 & -2.532 & 0.012 \\
\hline $\mathrm{AC}$ & 0.456 & 2.453 & 0.015 \\
\hline
\end{tabular}

${ }^{*}$ The New established equation is as follows: $\mathrm{EFW} \_$FLHCAC $=\{(-1.844)+(\mathrm{FL} \times 0.661)+(\mathrm{HC} \times-0.470)+(\mathrm{AC} \times 0.456)\} .{ }^{*}$ This question shows the fetal biometry used to estimate fetal weight for Sudanese and their correspondent coefficient in addition to the intercept of the equation (constant)).

in a study done in Sri Lankan to predict newborns less than $2.5 \mathrm{~kg}$ [13].

This descriptive study demonstrated that fetal weight could be estimated accurately and reliably by ultrasonography examination, using any of the six formulae while the Hadlock l, III and IV formula are the most accurate formula for estimation of fetal weight (Table 2).

In this study we developed a new equation $\mathrm{EFW}_{\mathrm{FL} \mathrm{HC} \mathrm{AC}}$ using multiple regression analysis where FL, HC and AC showed strong correlation with fetal weight, hence the new established equation as $\left(\mathrm{EFW}_{\mathrm{FLHCAC}}=-1.844+\right.$ $(\mathrm{FL} \times 0.661)+(\mathrm{HC} \times-0.470)+(\mathrm{AC} \times 0.456)$, which works well for Sudanese, since the fetal biometry used was indigenous; therefore it is the best formula identified in our study to predict Sudanese babies weight ranged between $1.86 \mathrm{Kg}$ to $3.987 \mathrm{Kg}, \mathrm{R}^{2}=0.913$ (Table 2, Table 3 and Figure 7). Our study was undertaken in order to provide the sonologist with new reference equation compatible with their practice. This new reference equation 


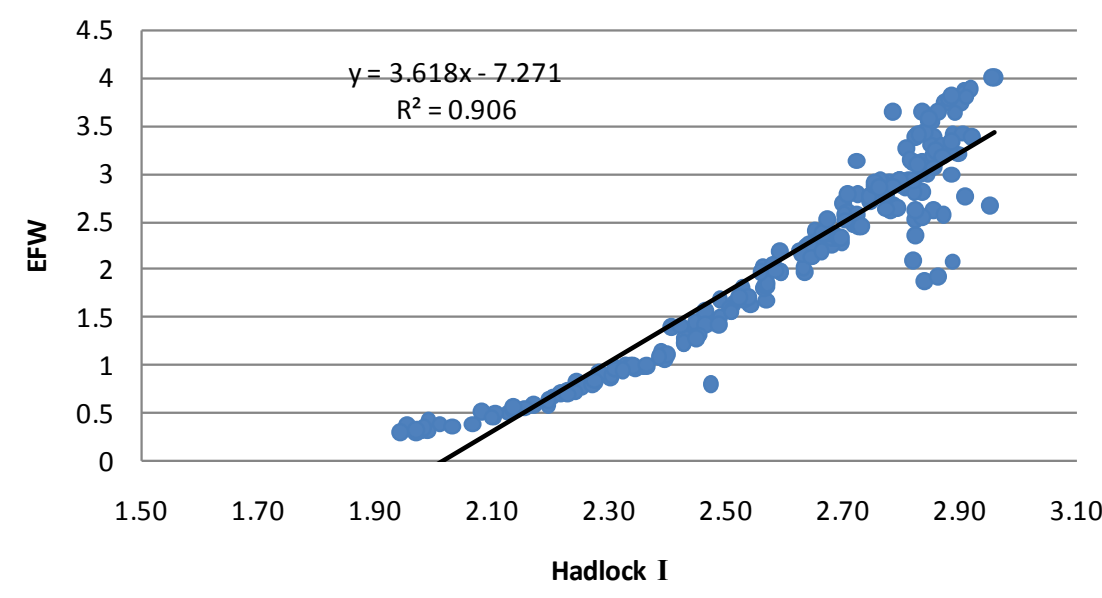

Figure 1. Shows a linear relationship between the estimated fetal weight and estimated fetal weight measured by Hadlock I equation for measuring of the fetal weight. $\mathrm{R}^{2}=0.906$, sig at $\mathrm{p} \leq 0.005(0.000)$.

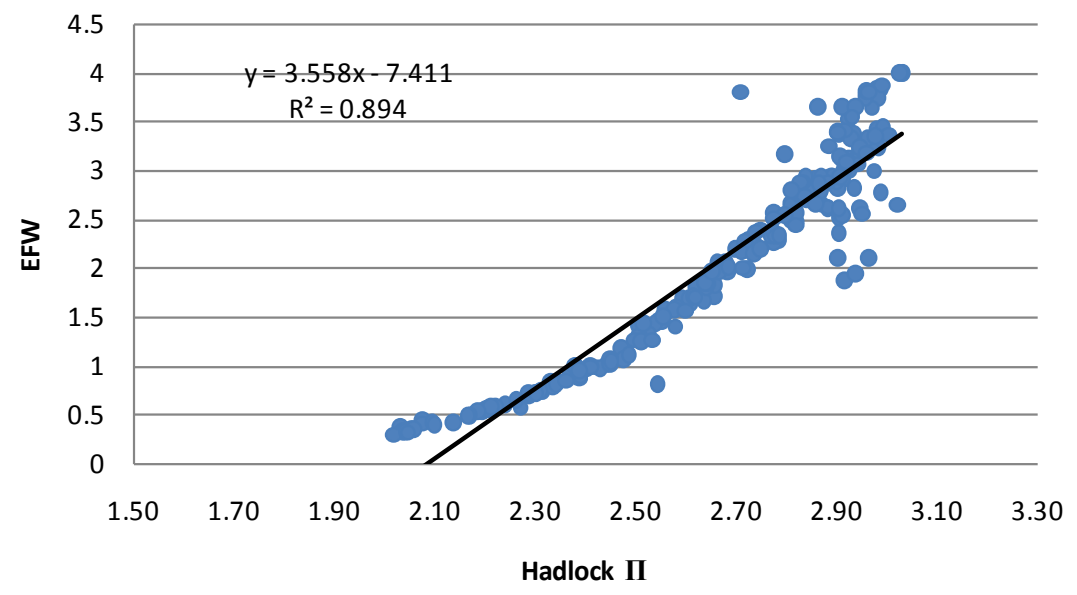

Figure 2. Shows a linear relationship between the estimated fetal weight and estimated fetal weight measured by Hadlock $\Pi$ equation for measuring of the fetal weight. $\mathrm{R}^{2}=0.894$, sig at $\mathrm{p} \leq 0.005(0.000)$.

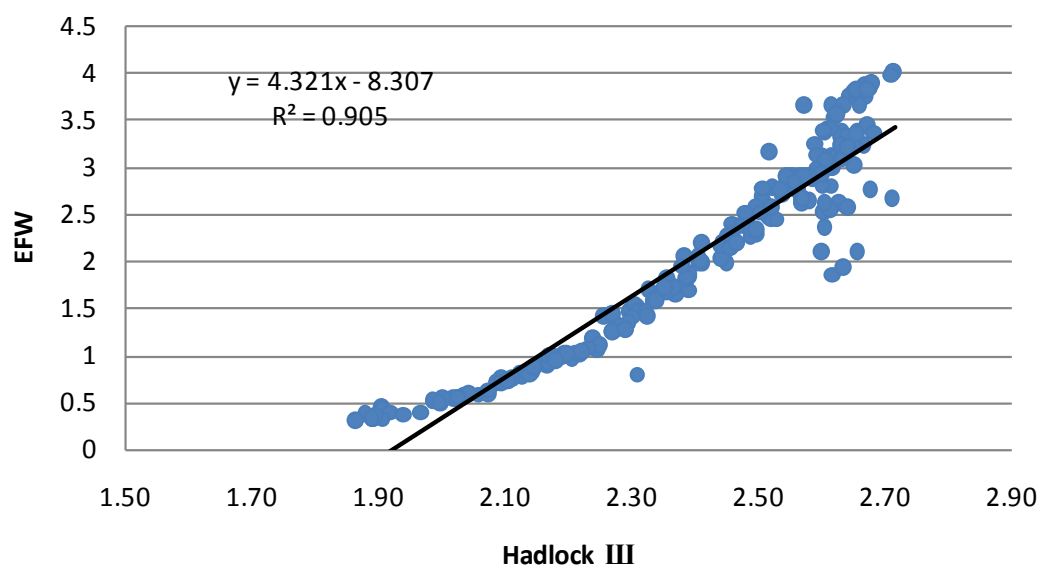

Figure 3. Shows a linear relationship between the estimated fetal weight and estimated fetal weight measured by Hadlock III equation for measuring of the fetal weight. $\mathrm{R}^{2}=0.905$, sig at $\mathrm{p} \leq 0.005(0.000)$. 


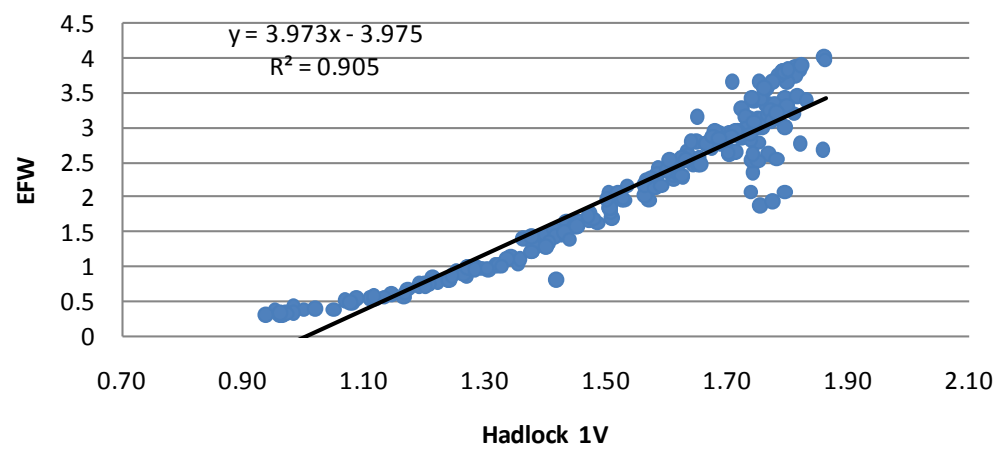

Figure 4. Shows a linear relationship between the estimated fetal weight and estimated fetal weight measured by Hadlock $1 \mathrm{~V}$ equation for measuring of the fetal weight. $\mathrm{R}^{2}=0.905$, sig at $\mathrm{p} \leq 0.005(0.000)$.

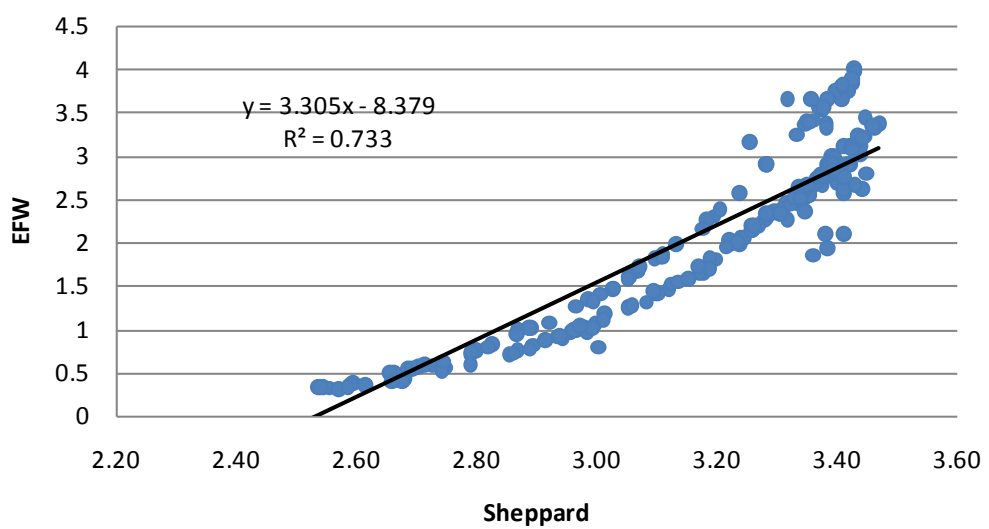

Figure 5. Shows a linear relationship between the estimated fetal weight and estimated fetal weight measured by Sheppard equation for measuring of the fetal weight. $\mathrm{R}^{2}=0.733$, sig at $\mathrm{p} \leq 0.005(0.000)$.

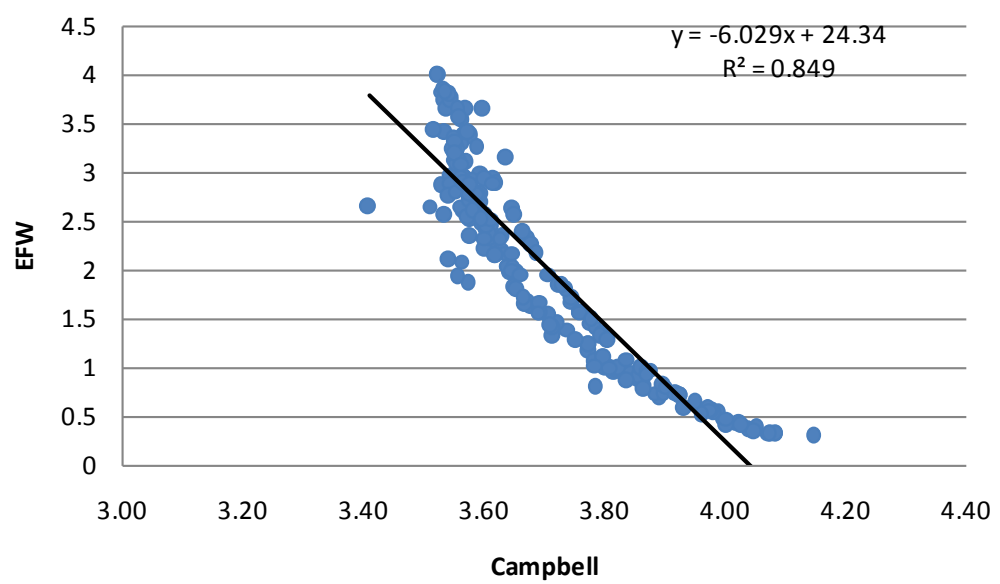

Figure 6. Shows a linear relationship between the estimated fetal weight and estimated fetal weight measured by Campbell equation for measuring of the fetal weight. $\mathrm{R}^{2}=0.849$, sig at $\mathrm{p} \leq 0.005(0.000)$.

is of great importance to all Sudanese fetuses, as fetal biometric values differ among ethnic groups [21]. In addition, the reference equation can be used in daily practice to scheme measurements on FW based on reference equation for newborn Sudanese population. The World Health Organization (WHO) recommended system for comparing individual anthropometric measurements with the reference population [22]. Therefore our study is 


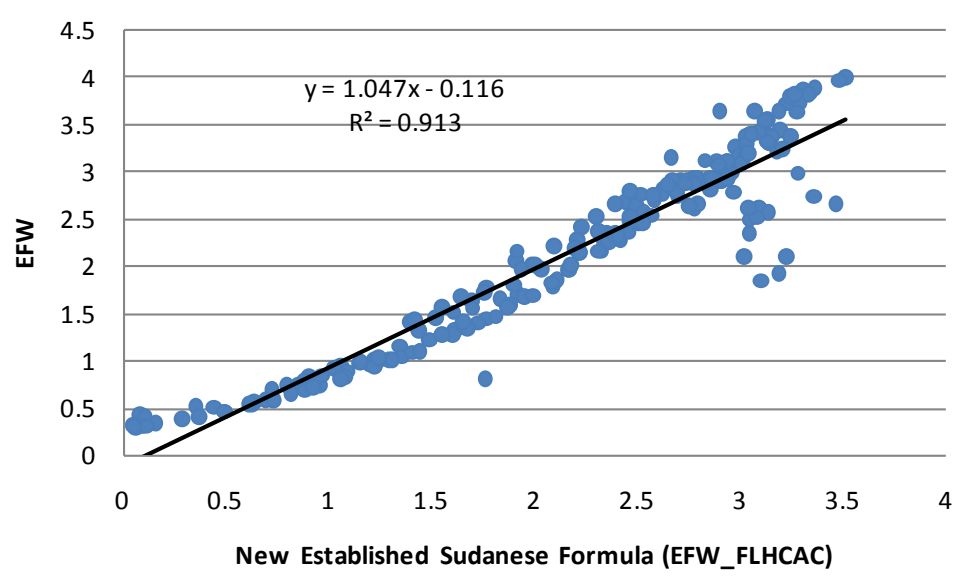

Figure 7. Shows a linear relationship between the estimated fetal weight and estimated fetal weight measured by New Established Sudanese equation for measuring of the fetal weight. $\mathrm{R}^{2}=0.913$, sig at $\mathrm{p} \leq 0.005(0.000)$.

an attempt to utilize this new and enhanced fetal weight equation as reference for Sudanese fetal weight which might help to define normal and abnormal growth in the neonatal population of Sudanese and thereby improve neonatal care. We hope this study contributes to daily practice in ultrasound clinics.

\section{References}

[1] Peregrine, E., O’Brien, P. and Jauniaux, E. (2007) Clinical and Ultrasound Estimation of Birth Weight Prior to Induction of Labor at Term. Obstetrics and Gynecology, 29, 304-309. http://dx.doi.org/10.1002/uog.3949

[2] Boyd, M.E., Usher, R.H. and Mclean, F.H. (1 983) Fetal Macrosornia: Risks, Proposed Management. Obstetric Gynecology, 61, 715-722.

[3] Bernstein, I.M., Horbar, J.D., Badger, G.J., Ohlsson, A. and Golan, A. (2000) Morbidity and Mortality among Very Low Birth Weight Neonates with Intrauterine Growth Restriction. American Journal of Obstetrics \& Gynecology, L82, 198-206.

[4] Edmonds, K. (2007) Dewhurst’s Textbook of Obstetrics and Gynecology. Wiley-Blackwell, London, 161-162.

[5] James, D.K., Steer, P.J., Weiner, C.P. and Gonik, B. (1999) High Risk Pregnancy Management Options. 2nd Edition, Bailliere Tindall, UK, 1133-1134.

[6] Nesbitt, T.S., Gilbert, W.M. and Herrchen, B. (1998) Shoulder Dystocia and Associated Risk Factors with Macrosomic Infants Born in California. American Journal of Obstetrics \& Gynecology, 179, 476-480. http://dx.doi.org/10.1016/S0002-9378(98)70382-5

[7] Sultan, A.H. and Stanton, S.L. (1996) Preserving the Pelvic Floor and Perineum during Child Birth—Elective Cesarean Section? British Journal of Obstetrics and Gynaecology, 103, 731-734.

[8] Campbell, S. and Wilkin, D. (1975) Ultrasonic Measurement of Fetal Abdomen Circumference in the Estimation of Fetal Weight. British Journal of Obstetrics and Gynaecology, 82, 689-697.

[9] Hadlock, F.P., Harris, R.B., Sharman, R.S., Deter, R.L. and Park, S.K. (1985) Estimation of Fetal Weight with the Use of Head, Body and Femur Measurements-A Prospective Study. American Journal of Obstetrics \& Gynecology, 75, 333-337.

[10] Warsof, S.L., Gohari, P., Berkowitz, R.L. and Hobbins, J.C. (1977) The Estimation of Fetal Weight by ComputerAssisted Analysis. American Journal of Obstetrics \& Gynecology, 128, 881-892.

[11] Shepard, M.J., Richards, V.A., Berkowitz, R.L., et al. (1982) An Evaluation of Two Equations for Predicting Fetal Weight by Ultrasound. American Journal of Obstetrics \& Gynecology, 142, 47-54.

[12] Hadlock, F.P., Harrist, R.B., Fearneyhough, T.C., et al. (1985) Use of Femur Length/Abdominal Circumference Ratio in Detecting the Macrosomic Fetus. Radiology, 154, 503. http://dx.doi.org/10.1148/radiology.154.2.3880915

[13] Kumara, D.M.A. and Perera, H. (2009) Evaluation of Six Commonly Used Formulae for Sonographic Estimation of Fetal Weight in a Sri Lankan Population. Sri Lanka Journal of Obstetrics and Gynecology, 31, 20-33.

[14] Medchill, M.T., Peterson, C.M., Kreinick, C., et al. (1991) Prediction of Estimated Fetal Weight in Extremely Low Birth Weight Neonates (500-1000 g). Obstetrics and Gynecology, 78, 286-290. 
[15] Pielet, B.W., Sabbagha, R.E., MacGregor, S.N., et al. (1987) Ultrasonic Prediction of Birth Weight in Preterm Fetuses: Which Formula Is Best? American Journal of Obstetrics \& Gynecology, 157, 1411-1414. http://dx.doi.org/10.1016/S0002-9378(87)80234-X

[16] Robson, S.C., Gallivan, S., Walkinshaw, S.A., et al. (1993) Ultrasonic Estimation of Fetal Weight: Use of Targeted Formulas in Small for Gestational Age Fetuses. Obstetrics and Gynecology, 82, 359-364.

[17] Royal College of Obstetricians and Gynecologists (2002) The Investigation and Management of the Small-forGestational-Age Fetus. Guideline No. 31. RCOG, London.

[18] Nahum, G.G. and Stanislaw, H. (2003) Ultrasonographic Prediction of Term Birth Weight: How Accurate Sit? American Journal of Obstetrics \& Gynecology, 188, 566-573.

[19] Venkat, A., Chinnaiya, A., Gopal, M. and Mongelli, J.M. (2001) Sonographic Fetal Weight Estimation in a South-East Asian Population. Journal of Obstetrics and Gynaecology Research, 27, 275-279.

[20] Siemer, J., Peter, W., Zoliver, H., Hart, N., Muller, A., Maurer, B., Goecke, T. and Schild, R.L. (2008) How Good Is Fetal Weight Estimation Using Volumetric Methods? Ultraschall in der Medizin, 29, 377-382.

[21] Jacquemyn, Y., Sys, S.U. and Verdonk, P. (2000) Fetal Biometry in Different Ethnic Groups. Early Hum Dev, 57, 1-13. http://dx.doi.org/10.1016/S0378-3782(99)00049-3

[22] WHO (1995) Physical Status: The Use and Interpretation of Biometry. In: Report of a WHO Expert Committee (WHO Technical Report Series No. 854), World Health Organization Press, Geneva, 121-155. 